\title{
NORMAS PARA LOS COLABORADORES DE LA REVISTA VENEZOLANA DE GERENCIA (RVG)
}

1. Debe enviarse al Director de la Revista: Comunicación firmada por todos los autores; diskette en programa word, identificado plenamente en la etiqueta; original y tres copias del trabajo. Cuando éste no es de Maracaibo se acepta por vía correo electrónico y debe enviarse simultáneamente copia a los coautores.

2. La RVG sólo considerará trabajos inéditos y que no se encuentren en proceso de arbitraje en otras revistas. El no cumplimiento de esta norma será sancionado con la suspensión indefinida de los autores en la RVG. No se aceptan trabajos que constituyan propuestas para cambiar la realidad, sin que el mismo no esté soportado por la investigación que de cuenta de la realidad para la cual se proponen los cambios.

3. Los trabajos serán evaluados considerando estas normas, así como los aspectos y criterios expuestos en las instrucciones para los árbitros (Ver instrucciones). El Comité Editorial se reserva la posibilidad de flexibilizar estas normas e instrucciones para los ensayos, dadas sus características.

4. Se consideran para su publicación: Artículos sobre resultados finales o parciales de investigación y Ensayos escritos por autores de reconocida trayectoria. Para la sección Gerencia al día, se aceptan los siguientes trabajos de extensión corta: 1) Comunicación rápida, para dar a conocer el derecho de propiedad intelectual; 2) Notas técnicas que describan procesos tecnológicos gerenciales; 3) Cartas al editor con opiniones sobre tópicos nuevos o problemas coyunturales en el campo gerencial; 4) Noticias que ofrezcan información actualizada sobre eventos científicos, proyectos de investigación y post-grados en temas gerenciales o afines; 5) Bibliografía sobre temáticas gerenciales y 6) Reseñas que contengan análisis o comentarios de literatura científica reciente.

5. La extensión de los artículos tendrá un mínimo de 20 páginas y un máximo de 35 , letra arial 12 , a doble espacio en papel tamaño carta, con numeración consecutiva de todas las páginas, incluyendo la portada, las tablas, cuadros y gráficos. El Comité Editor podrá autorizar trabajos de más de 35 páginas cuando lo considere pertinente.

6. La portada de los artículos debe contener: 1) Título en español e inglés; 2) Apellidos y nombres separados por coma (máximo 4 autores), ordenados de acuerdo al aporte; 3) Resumen (máximo 15 líneas) en español e inglés, el cual debe contener, breve introducción, objetivos, metodología, resultados y conclusiones; 4) Un máximo de cinco y un mínimo de tres palabras clave en español e inglés; 5) Institución de apoyo financiero y agradecimiento si fuese necesario y 6) Currículo a pie de página, que contenga (en tres líneas por autor), ocupación, institución y dirección electrónica, indicando el autor para la correspondencia.

7. El cuerpo del artículo debe dividirse en las siguientes secciones: a) Introducción: Que incluya al menos: Problemas de la realidad y del conocimiento sobre el objeto de estudio que justifican la elaboración del trabajo, objetivos del trabajo y metodología, así como aspectos teóricos cuando no se discu- 
ten en sección separada, b) Desarrollo: constituida por secciones y subsecciones (éstas deben evitarse), identificadas con números arábigos, de acuerdo al sistema decimal, comenzando con el número 1 para la introducción y el último número para las conclusiones. Los títulos de las secciones y subsecciones deben dar cuenta del contenido del trabajo, manteniendo la proporción entre las secciones, cuando éstas tengan subsecciones deben tener una breve introducción al punto tratado. Las notas aclaratorias deben reducirse al mínimo necesario y hacerse al pie de la página donde se encuentra la llamada. En el desarrollo deberá quedar claro el aporte del autor y c) Conclusiones.

8. Las citas deben realizarse en el texto y contener: Primer apellido, año: página. Ejemplos: a) De acuerdo a Bull (2004:572) o (Bull, 2004: 572) según el caso, b) Si son más de dos autores (Orozco et al, 2004:642). Cuando se refiere la idea global de una obra, no requiere número de página. Las citas de Internet deben mencionar autor (en caso de tenerlo), año, página, en su defecto la página web y la fecha de consulta. Para referencias de entrevistas en el texto deben aparecer entre paréntesis el apellido, entrevista y año de la entrevista, ejemplo: (López, entrevista 2003). Para referir información sin autor, contenida en prensa, debe ir de la siguiente manera: periódico, fecha abreviada, página de la sección, ejemplo: (Panorama, 07/11/2003: 1-3). Las leyes se citan así: Autor, año. Ejemplo: (Asamblea Nacional, 2000).

9. La bibliografía debe limitarse a fuentes citadas en el trabajo y evitar referencias a obras no publicadas. Deben coincidir las citas y las referencias bibliográficas. Presentarse en orden alfabético, cronológicamente si hay varias obras del mismo autor; si un autor tiene más de una publicación del mismo año, deben ordenarse literalmente (2004a y 2004b). El orden debe ser: Apellidos, Nombres (año de publicación), Título del artículo, Título del libro o revista en negritas, volumen, número, país, institución o editorial, pp y número de la primera y última página si se trata de artículo, Ejemplo: Guerrero, Omar (2004), El mito del nuevo "Management" público. Revista Venezolana de Gerencia, Año 9, No. 25, Venezuela, Centro de Estudios de la Empresa, Universidad del Zulia, pp 9-52. Cuando se trata de un autor institucional, colocar: Nombre completo de la Institución, siglas si es muy conocida, (Año), Título y Ciudad o País. Ejemplo: Banco Mundial BM (1993), Informe sobre el desarrollo mundial ¿Invertir en salud?, Washington D. C. Las fuentes de Internet deben mencionar autor y el título del trabajo (en caso de tenerlo), la página web y fecha de la consulta. Cuando se refiere a información de periódico que no tenga autor, se debe realizar de la siguiente manera: Nombre del periódico, fecha abreviada, Título del trabajo, Ciudad y País. Las leyes deben referirse así: Autor, nombre de la ley, medio de publicación, ciudad y país, Ejemplo. Asamblea Nacional de la República Bolivariana de Venezuela (2001), Ley Orgánica de la Administración Pública. Gaceta Oficial No. 37.305, Venezuela. Las referencias de entrevistas deben colocarse aparte dentro de la bibliografía, con el título: Entrevistas, y se refieren de la siguiente manera: apellidos, nombres; cargo (si procede), lugar de la entrevista y fecha. Ejemplo: López, Mirtha. Directora del Centro de Estudios de la Empresa; Maracaibo 10 de noviembre de 2003.

10. Las tablas (números), cuadros (palabras) y gráficos (diagramas, ilustraciones, figuras, flujogramas) deben elaborarse en escala de grises e insertarse inmediatamente después de referirse, estar numerados por orden de aparición, con título que de cuenta de su contenido, evitarse los innecesarios. No deben llevar líneas para separar las columnas, deben incluirse las ecuaciones aplicadas y mencionar la fuente de información al pie.

11. El Comité Editor se reserva el derecho de hacer las modificaciones de forma que considere necesarias.

12. No se aceptan anexos a los artículos.

13. Si usa acrónimos u otras siglas deberán ser en mayúscula y la primera vez que se menciona deberá escribir el nombre completo seguido del acrónimo o la sigla entre paréntesis. Ejemplos: Banco Central de Venezuela (BCV), Universidad del Zulia (LUZ).

14. Bajo ninguna circunstancia serán devueltos al autor los originales una vez que ingresen a la revista. 
Revista Venezolana de Gerencia (RVG)

Centro de Estudios de la Empresa

Facultad de Ciencias Económicas y Sociales

Universidad del Zulia (LUZ)

Maracaibo - Venezuela

\section{REVISTA VENEZOLANA DE GERENCIA Formato de Arbitraje de Artículos}

1. DATOS SOBRE EL TRABAJO

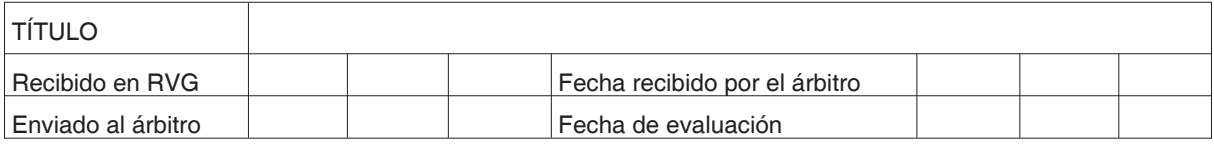

2. ARBITRAJE

\begin{tabular}{|l|l|l|l|l|l|}
\hline \multirow{2}{*}{ ASPECTO } & \multicolumn{3}{c|}{ CALIFICACIÓN } & \multirow{2}{*}{ JUSTIFICACIÓN } \\
\cline { 2 - 5 } & Exc. & Buen & Reg. & Def. & \\
\hline Título & & & & & \\
\hline Resumen & & & & & \\
\hline Palabras clave & & & & & \\
\hline Introducción & & & & & \\
\hline Desarrollo del Trabajo & & & & & \\
\hline Notas al pie de página & & & & & \\
\hline Conclusiones & & & & & \\
\hline Propuestas, si las hubiera & & & & & \\
\hline Tablas, cuadros y gráficos & & & & & \\
\hline Referencias bibliográficas & & & & & \\
\hline
\end{tabular}

\section{OPINIÓN GENERAL}

\begin{tabular}{|l|l|}
\hline Publicable sin modificaciones & \\
\hline Publicable con ligeras modificaciones & \\
\hline Publicable con modificaciones sustanciales & \\
\hline NO PUBLICABLE & \\
\hline
\end{tabular}

\section{DATOS DEL ÁRBITRO}

Nombre:

Institución:

Datos sobre el último trabajo publicado 


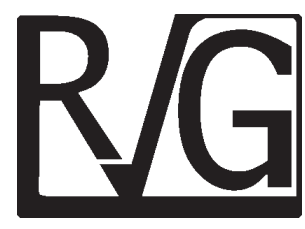

Revista Venezolana de Gerencia (RVG)

www.redalyc.uaemex. $m x$

www.serbi.luz.edu.ve/scielo

E-mail:rvgluz@yahoo.es

sorarincon@hotmail.com

Dirección: Apartado Postal No. 15401

Teléfono: (58-261) 7596720 


\section{REVISTA VENEZOLANA DE GERENCIA (RVG) INSTRUCCIONES A LOS ARBITROS}

\section{El trabajo debe cumplir las normas de la RVG y los criterios de evaluación ex-} puestos en estas instrucciones. La calificación de excelente en cada aspecto no necesita justificación, pero para el resto de calificaciones es necesario que explique puntualizando los problemas según los criterios. Cualquiera sea la opinión general, debe justificarla, utilice hojas adicionales si no le resulta suficiente el espacio del formato, y siga además las siguientes instrucciones para el llenado del formato de arbitraje:

\begin{tabular}{|l|l|}
\hline Aspecto a considerar & Criterios de evaluación además del cumplimiento de las normas \\
\hline Título & $\begin{array}{l}\text { 1. Debe dar cuenta de un objeto de investigación y no del objetivo, por lo } \\
\text { tanto no debe comenzar con verbo } \\
\text { 2. La extensión no debe exceder de doce palabras } \\
\text { 3. Debe dar cuenta del contenido del trabajo } \\
\text { 4. Evitar referencias de espacio muy específico, los cuales deben } \\
\text { incluirse en el resumen }\end{array}$ \\
\hline 5esumen & $\begin{array}{l}\text { 1. Todatar comenzar con un artículo o preposición } \\
\text { 2. No deben incorporarse abreviaturas, siglas, acrónimos, signos. } \\
\text { Fórmulas, códigos y símbolos. }\end{array}$ \\
& $\begin{array}{l}\text { 3. Breve introducción que justifique la temática } \\
\text { 4. Objetivos: Los objetivos generales de la investigación. } \\
\text { 5. Metodología: De modo sintético, debe contener referencias sobre el } \\
\text { método y técnicas utilizados en el proceso de investigación } \\
\text { 6. Resultados: Principales hallazgos proveniente del desarrollo del } \\
\text { trabajo. } \\
\text { 7. Conclusiones: Una síntesis de las conclusiones del trabajo. }\end{array}$ \\
\hline Palabras clave & $\begin{array}{l}\text { 1. Pueden ser palabras compuestas. } \\
\text { 2. No deben ser: siglas, acrónimos, símbolos o fórmulas. } \\
\text { 3. Pueden identificar países o lugares geográficos específicos } \\
\text { 4. Conceptualizan los principales temas tratados en el artículo. } \\
\text { 5. Deben facilitar la consulta del trabajo en las bases de dato por lo cual, } \\
\text { la selección adecuada es importante. }\end{array}$ \\
\hline Introducción & $\begin{array}{l}\text { 1. Justificación de la temática, considerando el problema del } \\
\text { conocimiento y/o de la realidad objeto de estudio } \\
\text { 2. Objetivos generales y los específicos si los hubiera } \\
\text { 3. Consideraciones teóricas y metodológicas que sustentan el trabajo, } \\
\text { aún cuando el trabajo sea teórico. } \\
\text { 4. La metodología debe exponerse claramente y contribuir a obtener resultados } \\
\text { que den cuenta de la realidad. De acuerdo al objeto de estudio el autor puede de- } \\
\text { sarrollar la teoría y el método en secciones separadas. }\end{array}$ \\
\hline
\end{tabular}




\begin{tabular}{|c|c|}
\hline Desarrollo del Trabajo & $\begin{array}{l}\text { 1. Uso correcto del idioma y su gramática } \\
\text { 2. Relación con los otras secciones del trabajo } \\
\text { 3. Organización interna coherente y equilibrada } \\
\text { 4. Los estudios sobre la realidad deben demostrarse empíricamente } \\
\text { 5. Toda información empírica debe tener la fuente y referente teórico } \\
\text { 6. No debe considerarse como referente teórico lo que el autor } \\
\text { considera el deber ser } \\
\text { 7. Los trabajos teóricos deben confrontar autores } \\
\text { 8. Debe quedar claro cuál es el aporte del o los autores del artículo } \\
\text { 9. Evitar incorporar data que no utiliza en el análisis } \\
\text { 10. La exposición debe respetar los derechos de autor }\end{array}$ \\
\hline Notas al pie de página & $\begin{array}{l}\text { Son sólo para aclarar o ampliar aspectos empíricos o teóricos que se discuten en } \\
\text { el desarrollo del trabajo }\end{array}$ \\
\hline Conclusiones & $\begin{array}{l}\text { 1. No deben constituir una repetición de los resultados } \\
\text { 2. Deben ser una reelaboración reflexiva de los resultados con alto nivel } \\
\text { de abstracción } \\
\text { 3. Es diferente a una reflexión final } \\
\text { 4. Evitar citas }\end{array}$ \\
\hline Propuestas si las hubiera & $\begin{array}{l}\text { 1. Deben surgir de los resultados de la investigación expuestos en el } \\
\text { trabajo } \\
\text { 2. No deben superar en número de páginas, del desarrollo del artículo }\end{array}$ \\
\hline Tablas, cuadros y gráficos & $\begin{array}{l}\text { 1. Las tablas, cuadros y gráficos, deben hablar por sí mismo, es decir no deben re- } \\
\text { querir para su comprensión de lectura del texto. } \\
\text { 2. Los títulos deben dar cuenta del contenido de la información } \\
\text { 3. Evitar título largos }\end{array}$ \\
\hline Referencias bibliográficas & $\begin{array}{l}\text { 1. Debe tener bibliografía reciente } \\
\text { 2. Debe tener referencias de publicaciones científicas periódicas }\end{array}$ \\
\hline
\end{tabular}

\section{OPINIÓN GENERAL}

\begin{tabular}{|l|l|}
\hline Calificativo & Criterios \\
\hline Publicable sin modificaciones & $\begin{array}{l}\text { El trabajo no tiene ningún tipo de observación, ni de forma } \\
\text { ni de fondo }\end{array}$ \\
\hline Publicable con ligeras modificaciones & $\begin{array}{l}\text { El trabajo amerita fundamentalmente modificaciones de } \\
\text { forma }\end{array}$ \\
\hline Publicable con modificaciones sustanciales & $\begin{array}{l}\text { El trabajo amerita importantes modificaciones de fondo } \\
\text { corregibles }\end{array}$ \\
\hline NEGADO & $\begin{array}{l}\text { El trabajo tiene problemas de forma y fondo cuya correc- } \\
\text { ción implica reelaboración del trabajo }\end{array}$ \\
\hline
\end{tabular}

